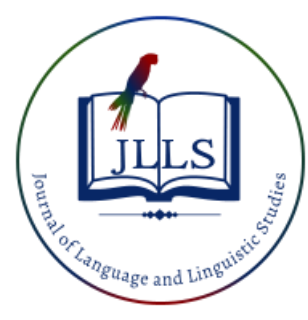

Available online at www.jlls.org

JOURNAL OF LANGUAGE

AND LINGUISTIC STUDIES

ISSN: 1305-578X

Journal of Language and Linguistic Studies, 17(4), 1806-1821; 2021

\title{
The search for national identity in the discourse analysis of YouTube comments
}

\author{
Tze Siew Liew a 1 iD, Hanita Hassan ${ }^{\text {b }}$ iD \\ ${ }^{a, b}$ Universiti Teknologi Malaysia, Johor Bahru, Malaysia
}

\section{APA Citation:}

Liew, T. S., \& Hassan, H. (2021). The search for national identity in the discourse analysis of YouTube comments. Journal of Language and Linguistic Studies, 17(4), 1806-1821. Doi: 10.52462/jlls.131

Submission Date:30/03/2021

Acceptance Date:15/06/2021

\begin{abstract}
YouTube is a popular social media site that provides the users a space to view, upload video clips or log in and write comments. Even though many of the YouTube users remain anonymous when commenting, their language use in the comments can reflect the identity of a particular community. Therefore, a variety of computermediated discourse can be obtained from YouTube in deciphering a specific community or a country's identity. This qualitative study is keen to investigate the representation of the Malaysian identity in the YouTube comments. Analysis were performed on the YouTube comments of Malaysian-related YouTube videos uploaded by famous Malaysian YouTubers. Textual analysis and coding of the YouTube comments were carried out using the NVivo software based on Herring's (2004) Computer-Mediated Discourse Analysis (CMDA) and Braun \& Clarke's (2006) Thematic Analysis framework. Findings showed that there were various themes that were repeated in the YouTube comments discourse which is a representation of the Malaysian identities, namely feelings of love towards the country, Malaysian cuisine, language mix, being multiracial, Malaysian behaviours or stereotypes, and the birth country Malaysia. These results provide insights into the discourse that are associated with Malaysian identities and contributed knowledge to fill in the gap in literature regarding national identity in social media, particularly Malaysia.
\end{abstract}

Keywords: computer-mediated discourse; language and identity; national identity; YouTube comments; codeswitching.

\section{Introduction}

Various forms of social media have emerged since the last decade and had taken over a large part of the users' lives, such as Twitter, Facebook, Instagram, LinkedIn, YouTube, Flicker, Reddit, and Yelp (Zarella, 2010). These social media sites are either people-focused or activity-focused (Keenan and Shiri, 2009, p.439) whereby sites that are people-oriented present profile pages that host the personal details and content about the user. On the other hand, sites which focus on the activities allow users to share and upload their content such as videos and photos. In contrast to traditional media that function in a one-way communication, social media allow users to express their views and ideas actively to each other (Mohd Faizal et al., 2014). Therefore, many people worldwide, especially the younger generation, opt to use social media to vent their emotions and express opinions. One

\footnotetext{
${ }^{1}$ Corresponding author.

E-mail address: tsliew87@gmail.com
} 
particular social media which allows users to express their views is YouTube. YouTube was started by Chad Hurley, Jawed Karim and Steve Chen in 2005 to provide a space for users to upload unrestricted amount of videos and to view others' videos. Since its acquisition by Google, it has been a popular choice of more than one billion users worldwide and has developed rapidly to become one of the largest video-sharing website on the Internet (Gill et al., 2007). According to Tankovska (2021), the site is the second most popular social media site in the world with more than two billion active users every month and videos are constantly uploaded onto the site every day. Multiple languages are used on YouTube and the users can freely voice out their opinions in the comments section of YouTube videos after registering and signing into their account. According to a Google survey, Malaysians spend double the amount of time watching YouTube than any other countries. The survey revealed that Malaysians aged between 16 and 34 years-old watch the most YouTube videos every month and many Malaysians spent time on the streaming site listening to music, watching movies and "how to fix" shows (Kaur, 2016). Thus, these YouTube computer-mediated discourse can be collected to better understand a specific community or nation's identity, which in this research refers to the Malaysian identity.

\subsection{Literature Review}

\subsubsection{The presence of identity in computer-mediated discourse}

There are various definitions to identity. Clark (2013) defined and viewed identity from the social, cultural, national as well as the individual perspectives. Riley (2007, p.86) on the other hand stated that "in social terms, identity is a quality which is ascribed or attributed to an individual human being by other human beings." According to Omar (2000), identity is a socio-psychological construct in which an individual or a group utilises certain symbols or features to identify themselves and others. Membership to a particular social group influenced the identity. This is because similar values, characteristics and common social identification methods are shared by members of a community. Therefore, generally, social sciences defined identity as how individuals regard themselves as belonging to a particular group. Examples of these groups are social identity, gender identity, cultural identity, religious identity, national identity. However, identity in psychology is based on an individuals' self-concept. In this study, we focus specifically on the national identity.

Identity can be constructed through the use of language. Johnstone (1996) have demonstrated that discourse in various forms can portray a person's sense of self or identity. Discourse is a term that refers to the process of language used by specific discourse (Lazebna, N., \& Prykhodko, A. 2021) communities, whether it is spoken, written or printed, within a sociocultural context of meaning production and reception (Kramsch, 2009). According to Schiffrin (2001), speakers used different types of communicative knowledge such as cognitive, expressive, social, textual to complement the grammatical knowledge of sound, form, and meaning in order to produce coherent discourse during interactions. Speakers are able to perform certain actions, convey meanings, form relationships and express attitudes as well as project personal and social identities through their discourse (Schiffrin, 2001). Some of these can also be brought into a computer-mediated environment, which is how the computer mediated discourse is generated. Computer-mediated discourse is the language employed by human beings when they interact with others by sending messages through a computer network and this type of discourse can reveal the speech community's identity.

As one of the pioneers in computer-mediated communication, Herring's (2000) work on language and gender establish the association between language and identity. Herring discovered distinct and organised differences in how males and females participated though their discourse styles (Panyametheekul and Herring 2003). A recent study by Vaisman (2014) had explored how gender or feminine identity was performed online through linguistic style choices such as beautiful script, cute 
spelling and glamorous words by Israeli girls on their blogs. Apart from that, spoken language features are found to belong to younger users and emoticons are frequently used by females in Witmer and Katzman's (1997) study and by male teenagers in Huffaker and Calvert's (2005) research. In addition, Androutsopoulos and Zieger (2004) demonstrated the way a particular location was associated with a certain language chat by investigating "Mannheim", a German city-chat and how it is linked to the regional speech. Androutsopoulos (2007) also did another study that identified deviant orthography and misspelling as the discourse and social identities of youth.

Apart from that, members of a particular computer-mediated community tend to express themselves with shared common language rules or characteristics. For example, some online communities do not allow flaming because they emphasise the use of polite language (Herring, 2004). Graham (2007) also agreed that those members belonging to a particular computer mediated community have to take note on such norms so that they can function as successful members of that said community. In fact, various research has indicated that age, gender and region can categorise online language use (Androutsopoulos and Ziegler 2004; Kapidzic and Herring, 2011). In terms of social media, users also bring with them their own backgrounds and cultures as they hail from all over the world (Kelly-Holmes \& Pietikäinen, 2012). When these users comment and post their thoughts on social media, their language used might indirectly reveal their identity as Page (2014) stated that identities of social media users can be identified through their typed words and images posted even though identity in social media is fluid and based on interaction. This shows that online users' real-life identities can be revealed even though some of them may try to hide their identities or gender. These identities are mostly detectable through their discourse (Herring, 2000).

Thus, this study's YouTube comments can therefore reveal the representation of Malaysian identity through the discourse of the users.

\subsubsection{The Malaysian Identity}

Malaysia, which is located in South East Asia, is a multicultural country that consists of three main ethnic groups as well as other minority ethnic groups. The population of Malaysia consists of the Chinese and Indians which are the minority group with a population of $22.8 \%$, while the Malay ethnic and the indigenous groups (majority from the eastern states of Malaysia of Sarawak and Sabah) make up $69.3 \%$ of the 32.6 million Malaysian population (Department of Statistics, Malaysia, 2020). All these different ethnic groups result in the richness and diversity of cultures and bring forth various ethnic and cultural identities in Malaysia.

Even though the Malays, Chinese and Indians and other native groups use and share the same official language and religion, each race has managed to retain its cultural identity through the maintenance of individual languages, religions and traditions (Tong and Robertson, 2008). The existence of various cultures, religions, and lifestyles have contributed significantly on how Malaysians perceive the nation as well as associate Malaysia with. According to a study conducted by Faiz (2002) on Malaysian students, the notion of their Malaysian identity are associated with factors such as geo-political, self, ethnocultural, linguistic, and religious identities. This kind of identity or representation of Malaysia can be brought onto social media sites such as YouTube when they interact with online users from all over the world. According to Smith (1991), national identity, a multidimensional concept, can be extended to include a specific language, sentiments and symbolism. Therefore, there can be various markers and themes that can constitute to being a Malaysian. 


\subsubsection{Past Studies on Social Media in Malaysia}

Social media usage has also been on the rise and has a prominent trend in South East Asian countries, including Malaysia which exhibits a high level of social media use. In 2010, Malaysia has the second-highest social network penetration in Southeast Asia (Stockdale \& Mclntyre, 2012).

In terms of YouTube studies concerning Malaysia, there has only been few studies conducted by Malaysian scholars. These researchers focused more on using YouTube as a tool for language learning (Hasan, 2013; Juhary, 2012), as a place for teaching and education of performing arts (Dorothy, 2013), and analysing YouTube use in university levels (Danyaro, Jaafar, De Lara \& Downe, 2010; Aripin et al., 2016). There was also one recent study by Lingam and Aripin (2017) that focused on flaming comments in Malaysian YouTube videos and discovered that racial and political attacks were the two most common YouTube comments. Therefore, there seems to be a gap in the literature for how the language is used in YouTube comments in relation to being a Malaysian, as well as a gap in linguistic representation or national identity of a nation based on YouTube comments. This study will be able to contribute knowledge to fill up the gaps in these areas.

\subsection{Research questions}

This study was part of a larger research to find out how the Malaysian identity is represented in the YouTube comments. The study sought for answers regarding the research question, "What are the discourse in YouTube comments which are associated with Malaysian identities?" The language expressions found in the comments of Malaysian related YouTube videos were analysed to check for the occurrences of any interesting linguistic findings.

\section{Method}

\subsection{Data sources}

Data sources were obtained from the comments of five YouTube videos related to the Malaysian identity uploaded by Malaysian YouTubers from year 2014 to 2017. Since the content generated by Malaysian YouTubers relates more to Malaysians and the Malaysian identity, the videos were selected only from them. Their videos on the Malaysian cultures and stereotypes could attract higher comments from Malaysian viewers in order to analyse the Malaysian identity. These YouTubers acted in the videos to depict the scenarios found in Malaysia. The lists of videos used for analysis of their comments are:

"How To Know You're Malaysian", uploaded on 28 Aug 2014 by The MingThing.

"What's So Great About Malaysia?" Uploaded on 22 Oct 2014 by JinnyboyTV

"Nine types of Malaysian Slang". Uploaded on 21 Sept 2015 by DanKhooProductions.

"Western Culture VS Malaysian Culture". Uploaded on 27 Aug 2017 by JinnyboyTV.

"What Malaysians complain about". Uploaded on 23 April 2017 by JinnyboyTV.

These videos were chosen as they fulfilled the requirements of having achieved the minimum number of views of 100,000 and have more than 100 comments as supported by Lingam \& Aripin (2017) in a similar study. These videos were also selected as their content prompt comments on the Malaysian identity. 


\subsection{Data collection and analysis}

Qualitative research was used to investigate how the Malaysian identity is portrayed in YouTube comments. This is because qualitative research is more suitable for this topic and this type of research allows for a more complex type of textual descriptions in looking into how people experience a particular research issue (Rwegoshora, 2014). Herring's sampling by theme for computer-mediated discourse was employed. The search for relevant videos were performed by typing in the words that are connected to the Malaysian theme such as "Malaysia", "Malaysian", "Malaysian culture" and "Malaysian identity". The chosen videos consist of videos about Malaysian food, people, culture, habits, lifestyles, language and stereotypes which could attract YouTube users to reply with comments to express their views on the Malaysian identity. In order for the discourse collected to be relevant and not outdated, a duration was set for the selection of the videos so that the chosen videos were sourced from year 2010 and onwards. Three hundred comments from each of the YouTube videos were collected until data saturation point. The total 1500 comments from the five videos were then analysed and coded using Nvivo by employing the qualitative method of textual analysis through Herring's (2004) Computer Mediated Discourse Analysis (CMDA) and Braun \& Clarke's (2006) Thematic Analysis framework. This research selected Herring's take on discourse analysis because this type of analysis is utilised when examining messages and interactions in a computer-mediated environment with textual evidence providing answers to the research questions (Herring, 2004:8). The use of Braun \& Clarke's (2006) Thematic Analysis for this study was to identify, analyse and report themes found within the texts. Themes for this study were devised based on the recurring patterns found in the comments through coding by textual analysis using Nvivo and irrelevant comments which do not fall into any themes were discarded from the study.

\section{Results}

When the comments were sorted out through thematic textual analysis, it was observed that there were a few categories of recurring themes in the discourse which were connected to the identity of Malaysia. The recurring themes included love towards the country, Malaysian food, Mixing languages in Malaysia, being multiracial, Malaysian stereotypes, and Malaysia as the birth country. The following sections illustrate these various categories of discourse discovered to represent the Malaysian identity.

\subsection{Love Towards the Country}

Despite frequent claims that Malaysians do not love their countries, analysis of the comments from the Malaysian videos portrayed a positive connotation on the Malaysian identity as the Malaysian users express their feelings and love towards the country. The following examples demonstrated the sense of patriotism towards the country by the users.

1) 1 Perangai 1 Malaysia

2) \#1Malaysia

The tagline "1 Malaysia", occurred repeatedly in various comments of the Malaysian associated YouTube videos, as shown in examples 1-4. In example 1, the Malay language with the words "1 perangai" which translates into "one same behaviour", conveys the notion that all Malaysians share the same characteristics, and this is part of the "1 Malaysia" identity. This showed that Malaysians in general appreciate being a Malaysian, are proud to be one and the tagline belongs to the Malaysian identity. 
3) hahahaha... so funny.. nice vid... 1 malaysia... together we are better !!! bersatu kita teguh bercerai kita roboh... (together we are stronger, separated we are weak)

4) why chinese speaking english sound slang like that? but its okay, never mine ;) 1Malaysia ;)

In example 3, the 1 Malaysia tagline is further amplified with the use of a Malay idiom at the end of the phrase (bersatu kita teguh bercerai kita roboh...) that expresses the strength in being united. In example 4, the user commented on the speaker in the video who had a Chinese accent when speaking English and accepting this as a part of the Malaysian culture through the use of the "1 Malaysia" tagline. The 1 Malaysia tagline was created by the Malaysian government to instil unity in the country and it seems that this has successfully foster feelings of unity and love for the country among the Malaysians, as found in the comments. In fact, the government have put in various efforts and organised campaigns to promote patriotism among Malaysians such as the introduction of Bahasa Malaysia (the Malay Language) as the official language and the "1 Malaysia" movement (Thurairaj, Mogan, Abas, Singh, Kumarasamy, 2018). Due to this, there were YouTube comments exhibiting love for the country, apart from being solicited by the content of the videos. The love towards the country was also demonstrated in the following examples.

5) I love Malaysia

6) I love my country... Semangat jiwaku. Aku bangga dan tak kesah kalau aku komen kat video yg sama dua kali. (The motivation of my heart. I am proud of my country and I do not mind even if I commented twice on the same video).

In examples 5-6, the users display directly how they love the country using the words "love". The user in example 6 even pointed out in Malay language that he is proud of Malaysia and does not mind even if he comments about this on the same video twice.

7) We are proud to be Malaysian!!!

8) Awesome! I'm so proud to be a Malaysian!

9) I am so proud that we can accept each other even we are different resist(races). (my English is bad...)"

Apart from the word "love", the expression "Proud" to be Malaysian were emphasised recurringly in examples 7-9. In example 9, the user mentioned the reason why he feels proud of the country, which is due to different races living together harmoniously. This attitude arises because of the integration effort put in by the Malaysian government. According to Chang and Kho (2017), integration is a process that unites people of various background and culture while retaining their own identities. The education system in Malaysia was utilised by the government as an integration tool to promote racial unity whereby the use of Malay language and a centralized school curriculum and examination was implemented (Chang and Kho, 2017). Apart from that, the role of media in projecting the image of 1 Malaysia helped in the integration process (Hassan et al., 2011). During the implementation of the campaign of 1Malaysia, the mass media bombarded the slogan and theme song for the campaign until the tagline of 1Malaysia was rooted deeply in the minds of many Malaysians. As a result, the love for Malaysia were displayed frequently in the comments through the 1 Malaysia taglines, expressions such as love Malaysia and proud of being a Malaysian.

\subsection{Food}

Food is commonly used as markers for identity even though many populations are divided by geographical, social and political differences (Adilah, Mohd Sallehuddin, Nurhasmilaalisa, Mohammed Haidrin, 2016). This is evident in Malaysia as Malaysia is a food heaven that offers a diverse culinary experience to Malaysians and tourists due to the heritage of our multicultural society. 
Since food is considered to be a huge aspect in the Malaysian identity, the talk on Malaysian food was rampant in the YouTube comments of videos related to Malaysia. Various words and feelings associated with food in the comments namely "love Malaysian food", "never hungry in Malaysia", "delicious food", displayed the love of Malaysians towards their food. The examples 10-13 below displayed this love for food among Malaysians.

10)@Nabil Zahrin wtfff... Malaysia is one of the best country in the world... We $r$ rich with food and culture...

11) We have so many Delicious things. Because Malaysia is a multi diverse country with different cultures. So our food is very diverse.

12) Thanks. Malaysia have many type of food due to multi races and culture. Malaysian is very creative and can create many unique and delicious food

13) The nasi lemak one... Represents about a decent portion of the Malay community.

These comments had a common thread of mentioning how diverse Malaysian food is due to Malaysia being a multicultural country. The comment in example 13 also demonstrated how nasi lemak (fragrant rice cooked in coconut milk) is perceived as tied to the Malay ethnic group and culture. This is in line with Alonso \& Krajsic (2013) who pointed out that a country's food establishes an essential identity of its people, as food represents not only physical need, but also a country's local cultures and customs. In Malaysia's case, the diverse races and local cultures have been represented in our food. Food is also sometimes used as a means of retaining our cultural identity, especially in Malaysia.

14) I'm Malaysian bc I love nasi lemak, roti canai and satay even though I sound American.

15) Im malaysian because I CHECK and i love mamak

As can be seen in examples 14-15, it can be inferred that the users perceive themselves as Malaysians due to their love for these famous Malaysian delicacies and cuisine such as nasi lemak (fragrant rice cooked in coconut milk), satay (seasoned skewered grilled meat), roti canai (flatbread). These foods initially originated from different ethnic groups' cuisine such as nasi lemak and satay from the Malays, and roti canai from the Indians. However, these dishes have been accepted, adapted and accultured by different ethnic groups in Malaysia (Noriza, Mohd Zahari, Shazali \& Rosmaliza, 2012). In example 14, it seems that the love for food in a Malaysian transcends the issue of accents and languages as the user mentioned that he or she is a Malaysian even though the individual does not speak like a Malaysian. Similar with the discourse on love towards the country, the word "love" is again used frequently in these comments to emphasise their passion for various Malaysian food that forms a part of their Malaysian identity.

There were also a few recurring or frequently mentioned famous or typical Malaysian food in the YouTube comments that consist of "Durian, "Nasi Lemak", "Mamak food", "Roti canai", and "Rendang" as shown in examples 16-19.

16) Malaysians loves durian yum!!!!!!!

17) Mamak is the best

18) I was waiting for the crispy chicken rendang ...

19) If u learn about nasi lemak more.....the real nasi lemak is very healthy and contain less calories

These foods are preferred by Malaysians and the positive tones towards them were detected in all these comments. A user in the comment of example 19 even tried to defend how healthy nasi lemak is which shows the great love of the users for the Malaysian food even though it might not be as healthy in reality. 
20) of course, every malaysian eats nasi lemak XD (im a fan of nasi lemak)

Besides that, one type of dish- "Nasi lemak" has won the hearts of Malaysians as there is a generalisation by a user that all Malaysians eat nasi lemak even though this might not be completely true. The staple "nasi lemak" is so synonymous with a Malaysian's food experience that the user did not think twice in pointing out that every Malaysian consumes this. In fact, food such as nasi lemak is listed as one of the most popular traditional foods as this food is mostly enjoyed by all races in Malaysia (Md Nor et al., 2012).

In short, these YouTube comments related to Malaysian food has reflected the Malaysian identity. Malaysians are united in our love for our nation's cuisine even though we hail from different culture, race, religion and background. Food can easily bring Malaysians together and this is seen as a form of identity for Malaysians. This is supported by Chong (2012) who stated that most countries try to safeguard their cultural food as a heritage as it helps to establish the core identity of a country. In Malaysia, a commonly shared food identity is used to identify as a nation and is integral in maintaining the Malaysian heritage and authenticity (Adilah, Mohd Sallehuddin, Nurhasmilaalisa, Mohammed Haidrin, 2016).

\subsection{Mixing Languages}

Language consists of codes and symbols utilised by humans to store, retrieve, organize, structure and communicate knowledge and experience. It is also used for the maintenance of a specific culture and to acquire a novel culture and knowledge (Lee, 2003). For example, when a person learns English to study overseas, he is also slowly understanding and acquiring knowledge about that specific culture as well.

Since Malaysians are multicultural, various types of languages are spoken and written in Malaysia. Many of the YouTube comments mentioned how Malaysians can speak various languages and how their identity is portrayed through the language used. Examples 21-24 demonstrated how language is integral to the Malaysian identity.

21) You should put that Malaysians can speak a few languages in one sentence.

22) It's true. Malaysian always like to speak improper English. Mix languages.

23) Where's the multiple language scolding?

24) You forgot something You know your Malaysian when... You know Chinese, English and Malay!!!

In examples 21-24, it is observed that the users associate speaking various languages as an essential part of being a Malaysian. Malaysians are regarded as commonly "mixing" languages or in other words codeswitching from one language to another or mixing a few languages in one sentence. Some users mentioned that even when we scold (example 23), Malaysians tend to utilise and mix different languages when reprimanding others, which is an example of code-switching. Various studies have found that Malaysians love to code-switch to maintain rapport, borrow from another language to express unknown words, or emphasise emotions (Asmah,1992, Norizah and Azirah, 2009, Dewaele and Wei, 2014). In fact, code-switching is common and synonymous with Malaysians as it is compulsory for Malaysians to learn at least two to three official languages of English, Malay and Chinese or Tamil in Malaysian schools.

\section{5) CAM SOMEBODY SPEAK MALAYSIA}


In example 25, it is also fascinating to find a user who identifies the unique style of using multiple languages in the country as the "Malaysia" language, probably signifying how this language can unite Malaysians.

All these findings on language being a part of the Malaysian identity are supported in Asmah's (1998) research to investigate whether there is a link between an individual's linguistic identity, ethnic heritage, and the place of linguistic identity among the three major ethnic groups in Malaysia (Malays, Chinese and Indians). Her research results revealed that an individual's linguistic identity is not inborn and fixed but can go through changes when the individual develops as a person, is influenced by the environment, and is altered according to the language of use. This suggests that the linguistic identity of an individual can stem from the influence of their cultural background and race, as well as to serve different functions, as in the case of the YouTube users whereby they might use language to express their sentiments towards the Malaysian related videos and as an important marker of being a Malaysian. This is also because most people will communicate in a language which will help them to retain their social and national identity (Clark, 2013), in this case, the Malaysian identity. This can be seen in example 26 below when the user questions if he is a Malaysian as he does not understand some Malaysian Chinese slangs from the video.

26) is it bad im malaysian and doesnt know what Aisheh or watever it is?

The user seems to feel guilty that he is not able to understand the Malaysian Chinese slang (Aiseh) even though he regards himself as a Malaysian. This proves the role of language in forming or influencing a person's perception of his cultural and national identity (Clark, 2013). In sum, the Malaysian identity cannot be separated from the multiple languages that we use and share. The findings in this section have revealed that users regard the Malaysian identity or being Malaysian as being multilingual, having the ability to mix multiple languages together in one sentence, as well as switching from one language to another language when conversing with other Malaysians. It is integral that the Malaysian style English discourse can still help to preserve the ethnic identity while establishing a national identity among Malaysians (Azirah, 2000).

\subsection{Being Multiracial}

As can be observed from the comments, Malaysians also perceive their identity as multiracial or as one, as Malaysia consists of different ethnic groups and cultures. To show this, some of the YouTube comments discussed the theme of being multiracial. Examples 27-29 present some of the common expressions used to address the multiracial element.

27) Malay Malaysians, Indian Malaysians, Punjabi Malaysians, Sabahan and Sarawak Malaysians.

28) The ultimate collab of Malaysian Youtubers. Multi racial and funny - a representation of Malaysia at its best!

29) Whys is Harith Iskandar's "Malaysians" are only Chinese? This is downright racism! I'm a Malay. How come no Malay Malaysians, Indian Malaysians, Punjabi Malaysians, Sabahan and Sarawak Malaysians?

All these comments illustrate how most YouTube users perceive Malaysia to be a multiracial country that include the ethnic groups of Malays, Chinese and Indians, as well as other ethnicities from the eastern states of Malaysia-Sarawak and Sabah. When these Malaysian-related videos include a collaboration of famous YouTube personalities from different races, some users commented how they were glad that this brings out the multi-racial scenario in Malaysia, as shown in example 28. In example 29, one of the users demanded modification on Harith Iskandar's (a famous Malaysian comedian) content in the video, insisting that he should have included and mentioned other races. This 
comment reflects the strong ties to the user's own cultural identity but at the same time the user still regards himself as a Malaysian. This is also in accordance with some studies that show that the national identity for all ethnic groups is Malaysian but the individual ethnic groups in Malaysia still possess their own ethnic and cultural identities, such as being Malays, Chinese, Indians and others (Azirah, 2000; Tong and Robertson, 2008).

30) What's so great about Malaysia? Racism.

31) Hye guys I'm Malaysian Malay, and don't agree...we are Malaysian. I know I'm half Malay and half Chinese cause I have Malay and Chinese blood from my father and 100\% Malay blood from my mom. I do not hate Malay, Chinese, Indian or others...but I just hate a racism in Malaysia. Hope Malaysia will be better in future.

32) This Is Malaysia. Don't call us an embarrassment. Don't call us a mistake. Don't call us racist. We are Malaysian. All of you must be jealous. We multiracial. Living together now.

33) "Not Malay, not Chinese, not Malays we are malaysiaaaaaa My MY MY"

Apart from that, when there is existence of various races in a nation, it is inevitable that racism will occur. Therefore, in the comments found in examples 30-33, many users acknowledge the issue of racism in Malaysia and implore for a stop to racism. Some users also urge others to regard Malaysia as one, instead of focusing on their own individual race. This can be supported by Liu, Lawrence, Ward, Abraham (2002) that noted that national and ethnic identity are group identities that can occur simultaneously or alternatively depending on the contexts and changing time. Therefore, Malaysians have embraced the Malaysian identity and treated the national identity as salient as the various ethnic identities to allow both to occur.

All these comments in this section portray the perception of the users that the Malaysian identity includes a multi-racial identity, and that Malaysians should also strive to achieve one collective identity, without succumbing to racism.

\subsection{Malaysian Stereotypes}

Stereotypes are how people perceive members of a particular group whether it is in terms of gender, ethnic and so on. These kinds of mental representations usually focus specifically on the differences between groups and minimise differences of people within the same group (MacLin and Herrera, 2006). Banaji (2001) also stated that the concept of stereotype refers to beliefs, knowledge, expectations towards social groups. Most of the times, stereotypes that we have towards another group are also related to experiences that we have encountered with one or two individuals of that group. In terms of Malaysian stereotypes, Malaysians have been labelled with quite a few as found in the comments.

When examining the comments, many YouTube comments discuss the various stereotypes towards Malaysians, due to some of the videos mentioning stereotypes and common experiences faced by Malaysians. Examples 34-36 highlight some stereotypes directed at Malaysians.

34) being late

35) on the way

36) Dia masih otw smpai skrg (He is still on the way until now)

The most common Malaysian stereotypes are shown in examples 34-36 as users respond in agreement with the videos about the stereotypes of Malaysians being late and the term "on the way". The stereotypes of Malaysians being always late are due to the common issue of some Malaysians who have a "Malaysian timing". Some Malaysians will mention that they are on the way to the 
destination when in actual fact, they have not started the journey. Thus, there are comments from a few users that mentioned how bad it is for Malaysians to have this bad habit and it is not something to be proud of as seen in examples 37-38.

37) I adore all of your vids guys honestly. But this one, somehow made me think twice. I literally feel like we have too much of 'special' bad habits. And don't u think we need to cut down on it? I mean, if we keep such habit in our daily life how are we going to be a decent future leader? I know im over thinking, but it's a fact that we all are facing today. GOSH I SOUNDED LIKE MY TEACHERS.

Ps. Don't u just hate it when someone is not punctual and u have to wait till the next hour for them. ( I'm sorry if im being too cynical)

38) Are these things something to be proud of?

The issue of punctuality has been taken lightly by many Malaysians and is a huge label for Malaysians. Nevertheless, despite the negative comment, most of the users still find these stereotypes or behaviours in examples 34-36 as a common unifying ground that identify them as Malaysian.

39) 1 Perangai 1 Malaysia

40) don't you love how we have that 1perangai that makes you know when another Malaysian is around

From examples 39-40, the users commented that Malaysians can be identified through behaviours that are unique to only Malaysians. The Malay word "perangai" or behaviour from the users assume that Malaysians commonly share certain behaviours that have been stereotyped as a national character. This is in accordance with what Azirah (2000) has discovered from the analysis of the discourse of a newspaper interview that some perceive "bangsa Malaysia" (the Malaysian identity) as constantly changing through the real-life experiences of the people. When different ethnic groups share common experiences, they also feel that they are bonded together through these experiences. Apart from that, as quoted by Riley (2007, p.86), "in social terms, identity is a quality which is ascribed or attributed to an individual human being by other human beings." Therefore, these behaviours encountered by the YouTube users could possibly lead to certain stereotypes towards Malaysians and could also be part of the Malaysian's social identity as it is a shared experience by many and is being attributed by others.

\subsection{Malaysia as the Birth country}

The origin or place of birth of an individual can mark their identity and influence their use of the language. Therefore, some comments associated with the birth country of Malaysia were also found during the data analysis.

41) What's so great about Malaysia? Each of us who are born and lived in Malaysia who are called Malaysian.

42) born and lived in Malaysia

43) Hah! I know Im a Malaysian because i was borned here!

Examples 41-43 revealed that most users agreed that being born in Malaysia constitute to being a Malaysian. The word "born" was mentioned multiple times in many of the comments. This is understandable as a person's home country will usually provide a sense of belonging and identity to the person as they have lived their entire lives in the country.

44) No sabahan and sarawakian tho, $i$ hope people know that sabah and sarawak are the part of Malaysia

Even though majority of the users agreed with the video and professed of being a Malaysian positively due to being born in Malaysia, there was a comment in example 44 which protested the 
content of the video that discussed the origin or the birth place of Malaysians as the videos did not consider their counterparts from East Malaysia: the Sarawakians and Sabahans. Sarawakians and Sabahans are residents from the eastern part of Malaysian and are usually neglected compared to their western Malaysian counterparts. It is intriguing to find out that many East Malaysians feel a sense of belonging to Malaysia but a certain amount of people from West Malaysia are not aware of the existence and lifestyles of East Malaysians. Their strong sense of belonging can be seen in the examples $45-46$ below.

45) love malaysia proud be malaysian i am from sabah.

46) I'm from the bumi kenyalang and I love being Sarawakian and Malaysian

In fact, all these comments show that many Malaysians, whether they are east or west Malaysians have a strong sense of identity of being a Malaysian through their birth country. This is supported by Faiz (2002) that lists geographical location as one of the important aspects of the Malaysian identity. For many people, their country of origin constitutes to their sense of identity and this is found even in immigrants from other countries (LaBarbera, 2015). Therefore, birth country can be identified as a part of the Malaysian identity.

\section{Conclusions}

In summary, the study investigated the representation of the Malaysian identity in YouTube comments of Malaysian-related videos. The discourse from YouTube comments revealed that the Malaysian identity is associated with the recurring markers of love towards the country, food, language, being multiracial, Malaysian stereotypes, and birth country. Some of these markers have revealed how cultural and national identity can be reflected through the YouTube comments. Although most of the comments portray a positive side of being Malaysian, there were also some comments highlighting the negative parts such as racism and how Malaysians need to reflect on the stereotypes of negative behaviours that they are being labelled with.

The limitations of the current study were some of the comments might be driven by the content of the videos which discuss the recurring categories. However, most users express their views on the video content, and this still contribute to how the users perceive the identities associated with Malaysia. Future research could possibly examine different genres of YouTube videos and analyse not only the discourse but other parameters such as emoticons and symbols to yield more data on national identity in YouTube comments. Overall, the research has provided interesting findings on the computer-mediated discourse found in YouTube comments that relates to the Malaysian identity.

\section{References}

Ramli, A. M., Zahari, M. S. M., Halim, N. A., \& Aris, M. H. M. (2016). The knowledge of food heritage Identithy in Klang Valley, Malaysia. Procedia-Social and Behavioral Sciences, 222, 518527. DOI: 10.1016/j.sbspro.2016.05.145

Alonso, A. D., \& Krajsic, V. (2013). Food heritage down under: olive growers as Mediterranean 'food ambassadors'. Journal of Heritage Tourism, 8(2-3), 158-171.

Androutsopoulos, J., \& Ziegler, E. (2004). Exploring language variation on the Internet: Regional speech in a chat community. In Britt-Louise Gunnarsson, Lena Bergstrom, Gerd Eklund, Staffan Fridell, Lise H. Hansen, Angela Karstadt, Bengt "Nordberg, Eva Sundgren and Mats Thelander (eds.) Language Variation in Europe. Uppsala, Sweden: Uppsala University Press, 99-111. 
Androutsopoulos, J. (2008). Style online: Doing hip-hop on the German-speaking Web. In Style and social identities (pp. 279-320). De Gruyter Mouton.

Aripin, N., Ismail, A., Ishak, M. S., Rahman, N. A. A., Rahman, M. N. A., Madon, M., \& Mustaffa, M. F. (2016). "YouTube" dan generasi muda Islam: Satu pendekatan kelompok fokus dalam kalangan pelajar universiti. Jurnal Komunikasi - Malaysian Journal of Communication, 32(1), 165188.

Omar, A. H. (1992). The Linguistic Scenery in Malaysia. Kuala Lumpur: Dewan Bahasa dan Pustaka. Beccari, O.[1904] 1982. Wanderings In The Great Forests Of Borneo.

Omar, A. H. (1998, October). Linguistic expressions and identity features: An investigation into the place of identity in the individual and the group. In third International Conference of the Faculty of Language Studies on 'The Role of Language in a Borderless World', Universiti Kebangsaan Malaysia, Kuala Lumpur.

Omar, A. H. (2000). Linguistic expressions and identity features: An investigation into the place of identity in the individual and the group. Language and Globalisation, Longman.

Hashim, A. (2000, December). 4 Culture and identity in the English discourses of Malaysians. In NOTE 311p.; Selected papers presented at the Annual South East Asia Conference (5th, Perth, Western Australia, Australia (p. 75). Retrieved from https://www.researchgate.net/publication/261700134_4_Culture_and_identity_in_the_English_dis courses_of_Malaysians.

Banaji, M. R. (2002). Stereotypes, social psychology of. International encyclopedia of the social and behavioral sciences, 15100-15104.

Braun, V., \& Clarke, V. (2006). Using thematic analysis in psychology. Qualitative Research in Psychology, 3, 77-101.

Casaló, L., Flavián, C., \& Guinalíu, M. (2007). Promoting Consumer's Participation in Virtual Brand Communities: A New Paradigm in Branding Strategy. Journal of Marketing Communications, 14(1), 19-36.

Chang, P.K., \& Kho, S.N. (2017). A Reflection of National Integration Process and the Role of Media in Malaysia. Jurnal Komunikasi (Malaysian Journal of Communication), Jilid 33(1), 395-405.

Chong, J. W. (2012). Mine, yours or ours?: The Indonesia-Malaysia disputes over shared cultural heritage. SOJOURN: Journal of Social Issues in Southeast Asia, 27(1), 1-53.

Clark, U. (2013). Language and Identity in Englishes. Oxon: Routledge.

Crystal, D. (2011). Internet Linguistics, London: Routledge.

Danyaro, K., Jaafar, J., De Lara, R., \& Downe, A. (2010). An evaluation of the usage of Web 2.0 among tertiary level students in Malaysia. IEEE Xplore Digital Library, 1-6.

Dewaele, J. M., \& Li, W. (2014). Intra-and inter-individual variation in self-reported code-switching patterns of adult multilinguals. International Journal of Multilingualism, 11(2), 225-246. doi:10.1080/14790718.2013.878347.

DeWitt, D., Alias, N., Siraj, S., Yaakub, M. Y., Ayob, J., \& Ishak, R. (2013). The potential of Youtube for teaching and learning in the performing arts. Procedia-Social and Behavioral Sciences, 103, 1118-1126. 
Department of Statistics, Malaysia. (2020). Current population estimates: Malaysia, 2019. https://www.dosm.gov.my/v1/index.php?r=column/cthemeByCat\&cat=155\&bul_id=aWJZRkJ4U EdKcUZpT2tVT090Snpydz09\&menu_id=L0pheU43NWJwRWVSZklWdzQ4TlhUUT09.

Faiz S. Abdullah. (2002). 'The state of being Malaysian.' In Rosli Talif (ed.), Shameem Rafik-Galea and S.H. Chan, Diverse Voices 2: Selected Readings in Language: 42-55. Serdang: Universiti Putra Malaysia Press.

Gill, P., Arlitt, M., Li, Z., \& Mahanti, A. (2007, October). Youtube traffic characterization: a view from the edge. In Proceedings of the 7th ACM SIGCOMM conference on Internet measurement (pp. 15-28).

Graham, S. L. (2007). Disagreeing to agree: Conflict, (im) politeness and identity in a computermediated community. Journal of pragmatics, 39(4), 742-759.

Hassan, H., Habil, H., \& Ibrahim, N.A. (2010). The Roles of Media in Realising 'Unity In Diversity'. International Proceedings of Economics Development and Research. www.ipedr.com.

Hasan, H. S. M. (2013). Using YouTube as a tool to learn verb tenses (Unpublished doctoral dissertation). Universiti Teknologi Malaysia.

Herring, S. C. (2004). Computer-mediated discourse analysis: An approach to researching online behavior. Designing for virtual communities in the service of learning, 338, 376.

Herring, S. C. (2000). Gender differences in CMC: Findings and implications. Computer Professionals for Social Responsibility Journal,18(1), 1-12. Retrieved from: http://www.cpsr.org/publications/newsletters/issues/2000/Winter2000/herring .html.

Huffaker, D. A., \& Calvert, S. L. (2005). Gender, identity, and language use in teenage blogs. Journal of computer-mediated communication, 10(2), JCMC10211. Retrieved from https://www.researchgate.net/publication/220437943_Gender_Identity_and_Language_Use_in_Te enage_Blogs.

Johnstone, B. (1996). The linguistic individual: Self-expression in language and linguistics. Oxford University Press.

Juhary, J. (2012). Online comments for language learning: a pilot study. Procedia Technology, 1, 297 302.

Kaur, M. (February 23, 2016). Malaysians watch more YouTube than anyone else in the world. New Straits Times. Retrieved from http://www.nst.com.my/news/2016/02/129141/msians-watch-moreyoutube-anyone-else-world

Kramsch, C. (2009). Language and Culture. Oxford: Oxford University Press.

Keenan, A., \& Shiri, A. (2009). Sociability and social interaction on social networking websites. Library review. 58(6) 438-450.

Kapidzic, S., Herring, S.C. (2011). Gender, Communication, and Self-Presentation in Teen Chatrooms Revisited: Have Patterns Changed?, Journal of Computer-Mediated Communication, 17(1), 39-59. https://doi.org/10.1111/j.1083-6101.2011.01561.x

Kelly-Holmes, H. (2012). Multilingualism and the media. In M. Martin-Jones, A. Blackledge, \& A. Creese (Eds.), The Routledge handbook of multilingualism (pp. 333-346). Abingdon: Routledge.

LaBarbera, M. C. (2015). Identity and migration: An introduction. In M. C. LaBarbera (Ed.), International perspectives on migration (pp. 1-13). Berlin, DE: Springer International Publishing. 
Lazebna, N., \& Prykhodko, A. (2021). Digital discourse of English language acquisition. Journal of Language and Linguistic Studies, 17(2).

Lee, S. K. (2003). Exploring the Relationship between Language, Culture and Identity. GEMA Online Journal of Language Studies, 3(2). Retrieved from http://ejournal.ukm.my/gema/article/viewFile/212/185.

Lingam, R. A., Aripin, N. (2017). Comments on Fire! Classifying Flaming Comments on YouTube Videos in Malaysia. Malaysian Journal of Communication, 33(4), 104-118. Retrieved from https://ejournal.ukm.my/mjc/article/view/22623/7483

Liu, J. \& Lawrence, B. \& Ward, C. \& Abraham, S. (2002). Social representations of history in Malaysia and Singapore: On the relationship between national and ethnic identity. Asian Journal of Social Psychology, 5(1), 3 - 20.

MacLin, M.K., and Herrera, V. (2006). The Criminal Stereotype. North American Journal of Psychology, 8(2), 197-208.

Mohd Faizal, K., Rosidayu, S., NorAdzrah, R. (2014). Can Twitter be an Effective Platform for Political Discourse in Malaysia? A Study of \#PRU13. Procedia - Social and Behavioral Sciences $155,348-355$.

Md Nor, N., Sharif, M. S. M., Zahari, M. S. M., Salleh, H. M., Isha, N., \& Muhammad, R. (2012). The Transmission Modes of Malay Traditional Food Knowledge within Generations. Procedia - Social and Behavioral Sciences, 50(0), 79-88.

Noriza, I., Zahari, M. M., Shazali, M. S., Rosmaliza, M., \& Hannita, S. (2012). Acculturation, foodways and Malaysian food identity. Current Issues in Hospitality and Tourism Research and Innovations, 359-363.

Hassan, N., \& Hashim, A. (2009). Electronic English in Malaysia: Features and language in use. English Today, 25(4), 39-46. doi:10.1017/S0266078409990435

Page, R. (2014). Hoaxes, hacking and humour: analysing impersonated identity on social network sites. In The language of social media (pp. 46-64). Palgrave Macmillan, London. https://doi.org/10.1057/9781137029317_3

Panyametheekul, S., \& Herring, S. C. (2003). Gender and turn allocation in a Thai chat room. Journal of Computer-Mediated Communication, 9(1), JCMC913. Retrieved from http://jcmc.indiana.edu/vol9/issue1/panya herring.html.

Sabate, C. P., Turney, E., \& Fleta, B. M. (2008). Orality and literacy, formality and informality in email communication. Ibérica, Revista de la Asociación Europea de Lenguas para Fines Específicos, (15), 71-88.

Riley, P. (2007). Language, culture and identity: An ethnolinguistic perspective. A\&C Black.

Schiffrin, D. (2001). Discourse markers: Language, meaning, and context. The handbook of discourse analysis, 1, 54-75.

Smith, A. D. (1991). National Identity. London: Penguin

Tankovska, H. (2021). Most popular social networks worldwide as of January 2021, ranked by number of active users. Statista. https://www.statista.com/statistics/272014/global-socialnetworks-rankedby-number-of-users/.(accessed Feb. 1, 2021). 
Stockdale, C., \& McIntyre, D. A. (2011). The ten nations where Facebook rules the Internet. Retrieved September, 2, 2014. Accessed on 20 Jan 2012, from: http://247wallst.com/2011/05/09/the-tennations-where-facebook-rules-theinternet/

Thurairaj, S., Mogan, S., Abas, A. M., Singh, K. K. S., \& Kumarasamy, J. (2018). The Meaning of Patriotism Among Malaysians: A Quantitative Study Towards Reinforcement of National Identity and Nation State. The Sultan Alauddin Sulaiman Shah Journal (JSASS), 5(2), 152-170. Retrieved from http://journal.kuis.edu.my/jsass/images/vol5bil2/jsass_vol5bil2_013_saraswathy.pdf.

Tong, M.C., \& Robertson K. (2008). Political and Cultural Representation in Malaysian Websites. International Journal of Design. Retrieved from http://www.ijdesign.org/ojs/index.php/IJDesign/article/viewFile/286/158

Vais, C. L. (2014). Beautiful script, cute spelling and glamorous words: Doing girlhood through language playfulness on Israeli blogs. Language and Communication, 34, 69-80.

Witmer, D. F., \& Katzman, S. L. (1997). On-line smiles: Does gender make a difference in the use of graphic accents? Journal of Computer-Mediated Communication 2(4). Retrieved from https://onlinelibrary.wiley.com/doi/full/10.1111/j.1083-6101.1997.tb00192.x

Zarrella, D. (2010). The Social Media Marketing Book. Canada: O'Reilly Media, Inc, 3.

\section{AUTHOR BIODATA}

Liew T. S. is currently a PhD student from the Language Academy in Universiti Teknologi Malaysia. She is also an English lecturer who delivers courses associated with language and communication in Malaysia. She possesses eight years of experience in designing teaching and learning materials as well as teaching preuniversity and undergraduate students in various types of English courses. She also holds a MA TESOL from the University of Liverpool.

Hanita Hassan is an associate professor and she is currently the Chair of Language Academy, Faculty of Social Sciences and Humanities. She has written and co-authored a few books, among others include Multimodal Communication of Corporate Website Design, New Perspectives in Language and Communication Research and English for Career Search. Her research interests include Systemic Functional Linguistics (SFL), multimodality, language in media, intercultural communication and ELT methodology. 